\title{
Ensaio de Citotoxicidade e Influência do Tratamento de Solubilização na Microestrutura da Liga Ti-35Nb-7Zr-5Ta para Potenciais Aplicações Ortopédicas
}

\author{
Taddei, E. B ${ }^{1}$, Henriques, V. A. R ${ }^{2}$, Silva, C. R. M $^{2}$, Cairo, C. A. A ${ }^{2}$, M. C. Bottino ${ }^{3}$ \\ ${ }^{1}$ Instituto Tecnológico de Aeronáutica - ITA/CTA, , São José dos Campos, SP. CEP. 12228-900 \\ e-mail: elisataddei@gmail.com \\ ${ }^{2}$ AMR- Divisão de Materiais - IAE/CTA, São José dos Campos, SP. CEP. 12228-900 \\ e-mail: vinicius@iae.cta.br, crmsilva@iae.cta.br, ccairo@iae.cta.br \\ ${ }^{3}$ Centro de Ciência e Tecnologia de Materiais, Instituto de Pesquisas Energéticas e Nucleares (IPEN), Cidade \\ Universitária, São Paulo, SP. CEP. 5508000 \\ e-mail: bottino@ipen.br
}

\begin{abstract}
RESUMO
A tendência das pesquisas atuais em próteses ortopédicas se baseia no desenvolvimento de ligas de titânio isentas de elementos com potencial tóxico e que possuam baixo módulo de elasticidade. Entre as ligas já desenvolvidas, a de composição Ti-35Nb-5Zr-5Ta se destaca das demais por apresentar o menor módulo de elasticidade, boa resistência mecânica e elevada biocompatibilidade. O processo de obtenção de ligas de titânio por metalurgia do pó (M/P) a partir dos pós elementares, mostra-se uma alternativa viável, por permitir a obtenção de peças com geometrias complexas e próximas às dimensões finais. Amostras da liga Ti-35Nb-5Zr-5Ta foram sinterizadas a $1500{ }^{\circ} \mathrm{C}$ por 2 horas, tratadas termicamente a $1100{ }^{\circ} \mathrm{C}$, por 3 horas, sob vácuo $\left(10^{-7}\right.$ Torr) e resfriadas no forno, visando obter uma microestrutura solubilizada. A avaliação biológica foi realizada a partir de um ensaio de citotoxicidade baseado na norma ISO 10993-5, usando cultura de células de ovário de hamsters chineses em contato com extratos diluídos de três diferentes materiais: PEAD (controle negativo), CP-Ti (referência clínica), a liga Ti-35Nb-7Zr-5Ta, e a solução fenólica a $0.2 \%$ (controle positivo). Os resultados do ciclo de tratamentos térmicos da liga são coerentes com a literatura e indicam um padrão microestrutural que se baseia na presença de grãos beta com precipitados de alfa nos contornos e no interior dos grãos. O teste "in vitro" revelou a não citotoxicidade da amostra sinterizada a $1500{ }^{\circ} \mathrm{C}$, demonstrando a segurança da rota utilizada na obtenção de implantes odontológicos e ortopédicos.
\end{abstract}

Palavras chaves: Titânio, citotoxicidade, metalurgia do pó, tratamento térmico

\section{Cytotoxicity and Influence of Solution Treatment on Microstructure of a Ti-35Nb-7Zr-5Ta Alloy for use in Orthopedics Prosthesis}

\section{ABSTRACT}

The trend of the current research in orthopedics prosthesis is based on the development of titanium alloys composed of non-toxic elements with low modulus of elasticity. The special interest in the Ti-35Nb$7 \mathrm{Zr}-5 \mathrm{Ta}$ alloy use for biomaterial applications is due to the lower modulus of elasticity, good mechanical strength resistance and superior biocompatibility. The process of titanium alloys production by powder metallurgy $(\mathrm{M} / \mathrm{P})$ from the elemental powders is a feasible route, for allowing the manufacture of parts with complex geometry and near to the final dimensions. Samples of Ti35Nb-7Zr-5Ta alloy were sintered at $1500^{\circ} \mathrm{C} / 2 \mathrm{~h}$, heat treated at $1100^{\circ} \mathrm{C}$ in vacuum $\left(10^{-7} \mathrm{Torr}\right)$ for 3 hours, followed by air and furnace cooling. The biological evaluation was carried out by a cytotoxicity test using Chinese Hamster Ovary (CHO) cultured cells in contact with diluted extract of three different sterile biomaterials: PEAD (negative control), $\mathrm{CP}-\mathrm{Ti}$, the alloy TNZT and phenol $0.2 \%$ (positive control). The extract preparation of the material involved in this investigation and the employed cell line were based on the International Standards Organization ISO 10993-5 (1992) guidelines. The results of the thermal treatments cycles of the TNZT alloy are coherent with literature and indicate a microstructural standard based on the presence of large beta grains with fine alpha precipitation in the grain boundaries and the interior of the grains. "In vitro" test indicated the non 
cytotoxicity of the Ti-35Nb-7Zr-5Ta alloy, demonstrating that the route and materials used is very secure for surgical implants production.

Keywords: Titanium, powder metallurgy, solution treatment

\section{INTRODUÇÃO}

A perfeita reconstituição de seções ósseas comprometidas após acidentes ou doenças se constitui num dos principais desafios da ciência moderna. As ligas de titânio se destacam entre os materiais para utilização em próteses ortopédicas por apresentarem elevada relação resistência mecânica/peso, boa resistência à corrosão e elevada biocompatibilidade. Entretanto, as ligas utilizadas atualmente apresentam um elevado grau de incompatibilidade biomecânica, por possuírem módulos de elasticidade (120 GPa) bastante superiores aos apresentados pelo osso $(\max .30 \mathrm{GPa})$, o que pode levar à falhas prematuras do implante [1, 2$]$.

As ligas de Ti beta metaestável constituem um dos grupos mais promissores de ligas de titânio em termos de processamento, propriedades e aplicações potenciais, apresentando os mais altos níveis de resistência mecânica, à fadiga e aos ambientes agressivos, mas não são indicadas para baixas temperaturas por apresentarem transformação dúctil-frágil [ㄹ-5 ]. Além disso as ligas dessa classe podem proporcionar uma grande variedade de fases e microestruturas, dependendo do tratamento térmico e de sua composição. São também passíveis de tratamentos térmicos (ou termomecânicos) realizados para a precipitação de fases adicionais. Normalmente, estes tratamentos incluem solubilização e envelhecimento para a precipitação das fases: alfa, ômega e/ou intermetálicos, que melhoram o limite de escoamento e a tenacidade a fratura. A morfologia, tamanho e distribuição destes precipitados determinam em grande parte as propriedades mecânicas da liga. Além disso, deformações a frio ou a quente podem ser utilizadas para modificar o comportamento da precipitação nessas ligas e dessa forma obter altas densidades de precipitados finos $[\underline{2}, \underline{6}]$.

Entre as ligas de titânio desenvolvidas recentemente, a de composição Ti-35Nb-5Zr-5Ta se destaca das demais por apresentar, boa resistência mecânica e elevada biocompatibilidade. Além de apresentar um dos menores valores de módulo de Young, o que é desejável no caso de aplicações biomédicas, uma vez que qualquer redução na rigidez do implante obtida pela substituição por novos materiais de menor módulo de elasticidade melhora a redistribuição de tensão no tecido ósseo adjacente, minimizando o efeito de escudo e prolongando o tempo de vida da prótese.

Portanto, o desenvolvimento de ligas beta de titânio despertaram um grande interesse no sentido da produção de biomateriais com baixo módulo de elasticidade, e ficou estabelecido que as ligas de titânio ideais para aplicações em implantes ortopédicos deveriam ter baixo módulo de elasticidade, elevada resistência à corrosão e nenhum potencial tóxico [7].

Esses fatores associados com a necessidade crescente de redução de custos de fabricação de componentes, principalmente, no que se refere ao titânio, levaram a produção de ligas de titânio por técnicas alternativas como a metalurgia do pó. Essa técnica utiliza pós de titânio de relativo baixo custo e processos de compactação de alta produtividade, obtendo-se materiais com boas propriedades mecânicas, além de possibilitar a obtenção de peças com porosidade controlada, que representa um fator importante para melhorar as características de osseointegração em implantes. Implantes porosos podem melhorar a estabilidade interfacial entre o biomaterial e o tecido ósseo. $\mathrm{O}$ aumento da área interfacial entre o implante $\mathrm{e}$ o tecido ósseo resulta no aumento da resistência à inércia ao movimento do implante no tecido. A porosidade também permite o abastecimento sangüíneo na superfície do implante, provendo de células osteoblastas a interface entre a superfície do biomaterial e o meio fisiológico [ㅁ-10]. A associação dessas propriedades torna mais atrativa a utilização de ligas de titânio em aplicações na área de biomateriais, como no caso da liga Ti35Nb-7Zr-5Ta [11] (Okazaki, Y., et al, 2001).

Dessa forma, foi realizado um estudo de solubilização da liga Ti-35-Nb-7Zr-5Ta obtida por metalurgia do pó, acompanhado de análise sobre a biocompatibilidade pelo método "in vitro" (citotoxicidade), utilizando-se cultura de células, visando utilização em próteses ortopédicas e odontológicas.

\section{MATERIAIS E MÉTODOS}

Amostras da liga Ti-35Nb-7Zr-5Ta foram obtidas pelo método "blended elemental" (BE), utilizando-se uma seqüência de prensagens uniaxial e isostática a frio, com subseqüente sinterização a vácuo, sendo os pós elementares obtidos pelo processo de hidrogenação. Após a mistura, os pós foram prensados uniaxialmente a frio em uma prensa manual, sob pressão de $60 \mathrm{MPa}$, em matrizes cilíndricas de $20 \mathrm{~mm}$ de diâmetro, com camisa flutuante.

A seguir, as amostras foram compactadas isostaticamente a frio após serem encapsuladas, sob vácuo, em moldes flexíveis de látex e introduzidas no vaso de pressão cilíndrico da prensa, sendo aplicada uma pressão de $350 \mathrm{MPa}$ por 30 segundos. 
Por fim, as amostras foram sinterizadas a $1500{ }^{\circ} \mathrm{C}$, em vácuo de $10^{-7}$ Torr com taxa de aquecimento de $20{ }^{\circ} \mathrm{C} / \mathrm{min}$. Após atingir a temperatura especificada, as amostras permaneceram nesse patamar por duas hora. Após essa etapa, as amostras foram aquecidas a $1100^{\circ} \mathrm{C}$ em vácuo $\left(10^{-7}\right.$ Torr $)$ por 3 horas e resfriadas ao ar e ao forno, visando obter-se uma microestrutura beta solubilizada.

A caracterização das amostras foi realizada com o auxílio de microscopia eletrônica de varredura e difração de raios-X. O lixamento das amostras seguiu a seqüência convencional de lixas. O polimento mecano-químico foi realizado em ácido oxálico. $\mathrm{O}$ ataque químico utilizado foi o Kroll, na seguinte proporção: $3 \mathrm{ml} \mathrm{HF}$ : $6 \mathrm{ml} \mathrm{HNO}_{3}$ : $100 \mathrm{ml} \mathrm{H}_{2} \mathrm{O}$. Foram realizados ensaios de microdureza Vickers nessas amostras por meio de um microdurômetro com penetrador piramidal de diamante de $136^{\circ}$. Foram feitas 15 impressões em cada amostra, com uma carga aplicada de $200 \mathrm{~g}$.

Testes de citotoxicidade foram realizados nas amostras sinterizadas a $1500{ }^{\circ} \mathrm{C}$ durante $2 \mathrm{~h}$. O ensaio fundamenta-se no procedimento originalmente desenvolvido por Borefreund \& Puerner (1984) [12] para a triagem de agentes citotóxicos em geral, sobre uma monocamada de células. O método é baseado na avaliação quantitativa de células vivas, após a exposição ao agente tóxico, pela incubação com o corante supravital do composto tetrazólio (MTS) e um agente acoplador de elétrons PMS. O MTS é biorreduzido pelas células a um produto que é solúvel no meio de cultura e, então, efetuada uma análise espectrofotométrica do corante incorporado, de acordo com Barltrop et al (1991) [13]. A quantidade de MTS, o marcador da viabilidade celular incorporada pela população de células, é diretamente proporcional ao número de células vivas na cultura.

No teste de citotoxicidade utilizou-se como controle positivo uma solução de fenol a $0,2 \%$. Como controle negativo, foram utilizadas amostras de polietileno de alta densidade (PEAD) e amostras de titânio comercialmente puro grau 2 (Conexão Sistemas de Prótese, São Paulo - Brasil), respectivamente, para o ensaio de toxicidade para os pós de partida e para as amostras sinterizadas. A preparação dos extratos, para os pós e para as amostras sinterizadas, foi realizada de acordo com a norma ISO-10993-5 (1993) [14] (ISO10993-5, 1993) deixando-se as amostras em contato com meio de cultura por $48 \mathrm{~h}$ em estufa a $37^{\circ} \mathrm{C}$ e com atmosfera úmida de $5 \%$ de $\mathrm{CO}_{2}$. Uma cultura de células de ovário de hamster chinês (CHO-K1) em monocamada foi separada por tripsinização. Em seguida, a suspensão celular foi centrifugada, lavada com solução tampão salina (PBS) estéril e o precipitado ressuspenso em meio RPMI 1640 contendo $10 \%$ de soro fetal bovino. Uma microplaca de cultura celular de 96 poços foi preparada a partir da adição de diluições crescentes $(6,25 ; 12,5 ; 25 ; 50 ; 100 \%)$ do extrato dos materiais testados $(50 \mu \mathrm{L} /$ poço, 4 poços/diluição). Em seguida, depositou-se por pipetação $50 \mu \mathrm{L}$ da suspensão celular ( $\sim 3000$ células) nos poços. O volume total em cada poço foi de $100 \mu \mathrm{L}$. Colunas controle de 4 poços foram preparadas: a) com o meio, mas sem a colocação das células (branco); e, b) meio e células, considerando-se 100\% a porcentagem de células vivas. Feito isso, a microplaca foi colocada em estufa $\left(37^{\circ} \mathrm{C}\right.$ sob atmosfera úmida de $\left.5 \% \mathrm{de} \mathrm{CO}_{2}\right)$ para incubação. Decorridas 72 h, $20 \mu \mathrm{L}$ de uma mistura (20:1) de MTS-0,2\% e PMS-0,09\% em PBS foi adicionada aos poços teste, deixando-se incubar por 2 horas. A incorporação do corante foi avaliada por um leitor de microplacas a 490 $\mathrm{nm}$ em relação ao branco.

\section{RESULTADOS E DISCUSSÃO}

A microestrutura das amostras da liga Ti-35Nb-7Zr-5Ta sinterizadas a $1500{ }^{\circ} \mathrm{C} / 2 \mathrm{~h}$ (Figura 1), apresentaram essencialmente um padrão de grãos beta, gerados a partir da total dissolução dos elementos estabilizadores desta fase (Nb e Ta), como já demonstrado em trabalhos anteriores [15-18] (Taddei, E. B, et al, 2003-2005). O valor de microdureza da liga apenas sinterizada sem tratamento térmico permaneceu na faixa de $350 \mathrm{HV}$. Pela análise de difração de raios - X (Figura 2), pode-se observar somente a presença dos picos das fases beta, não sendo observados nenhum pico relacionado a impurezas ou intermetálicos devido a alta concentração de estabilizantes beta dissolvidos $(\mathrm{Nb}$ e Ta).

As micrografias das amostras tratadas a $1100^{\circ} \mathrm{C}$ durante 3 horas e resfriadas ao ar são mostradas na Figura 3. Nota-se a presença de grandes grãos beta com precipitados de alfa nos contornos e no interior dos grãos. Com uma magnitude maior, observa-se claramente precipitados alfa. nos contornos de grão. As amostras resfriadas ao forno nesta mesma temperatura (Figura 3) apresentam o mesmo comportamento. Não foi observada uma significativa influência do aumento do tempo de patamar na microestrutura final. Os resultados das análises de microdureza nessas amostras tratadas a $1100^{\circ} \mathrm{C} / 3 \mathrm{~h}$, de acordo com o meio de resfriamento são de $479 \mathrm{HV}$ para as resfriadas ao ar e $402 \mathrm{HV}$ para as amostras resfriadas em forno. 


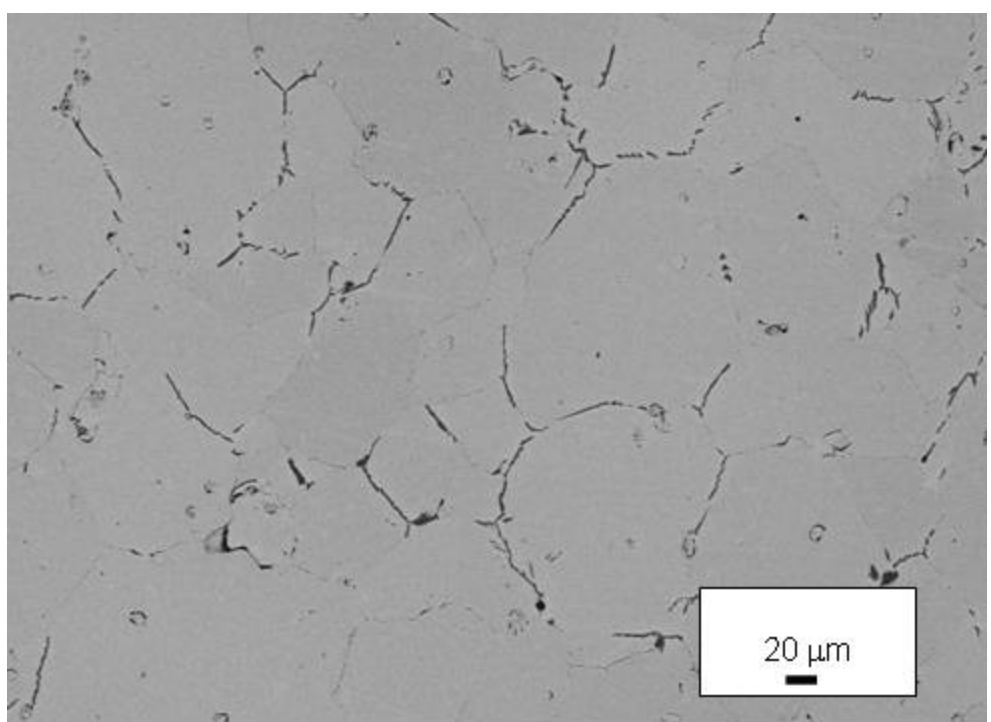

Figura 1: Micrografia de amostra da liga Ti-35Nb-7Zr-5Ta sinterizada a $1500{ }^{\circ} \mathrm{C}$ por duas horas.

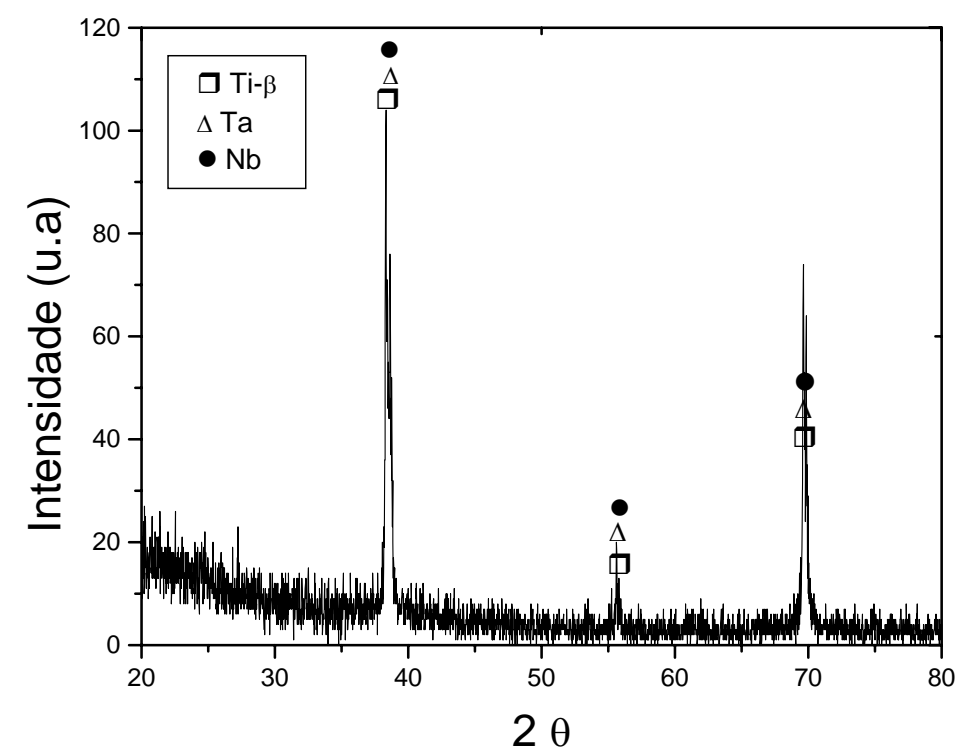

Figura 2: Difração de raios $\mathrm{X}$ da amostra da liga Ti-35Nb-7Zr-5Ta sinterizada a $1500{ }^{\circ} \mathrm{C}$ por duas horas. 

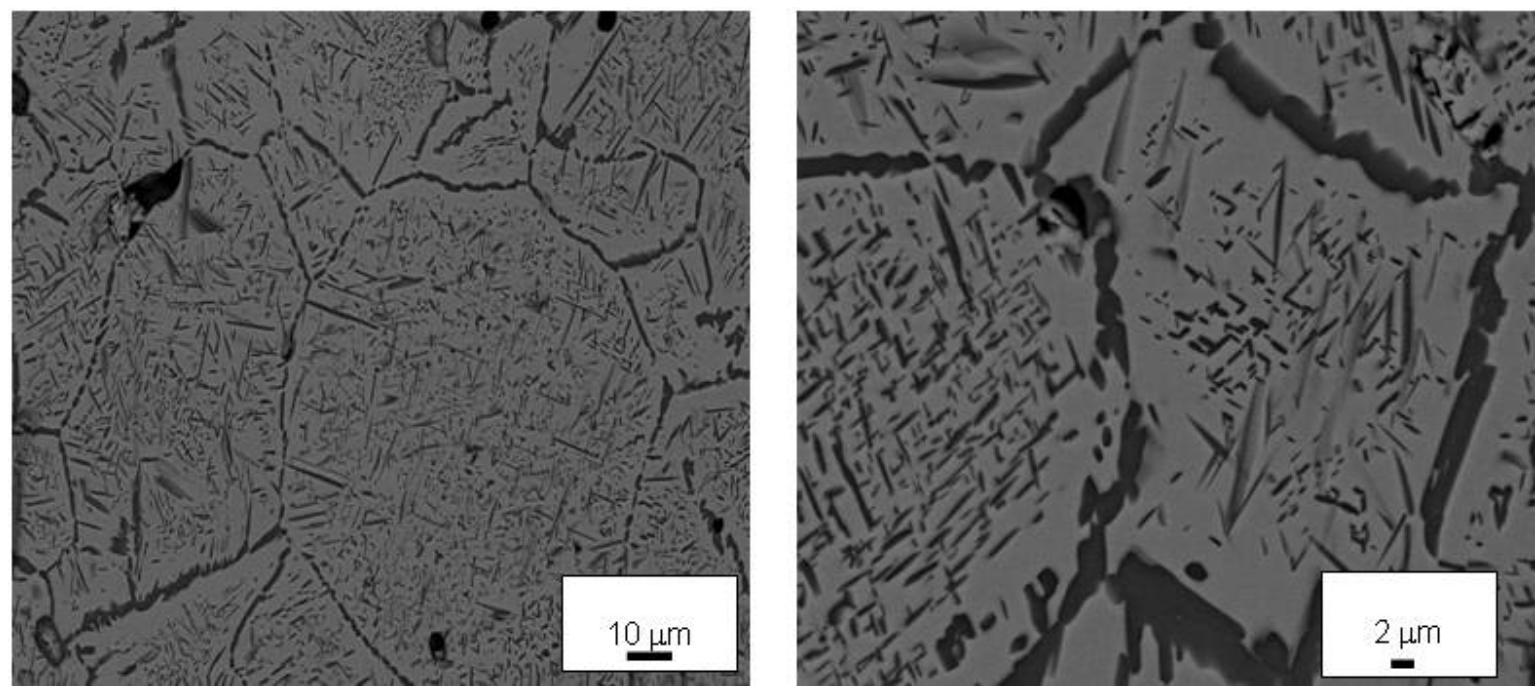

Figura 3: Micrografias das amostras da liga Ti-35Nb-7Zr-5Ta tratadas a $1100^{\circ} \mathrm{C}$ por três horas e resfriados ao ar.
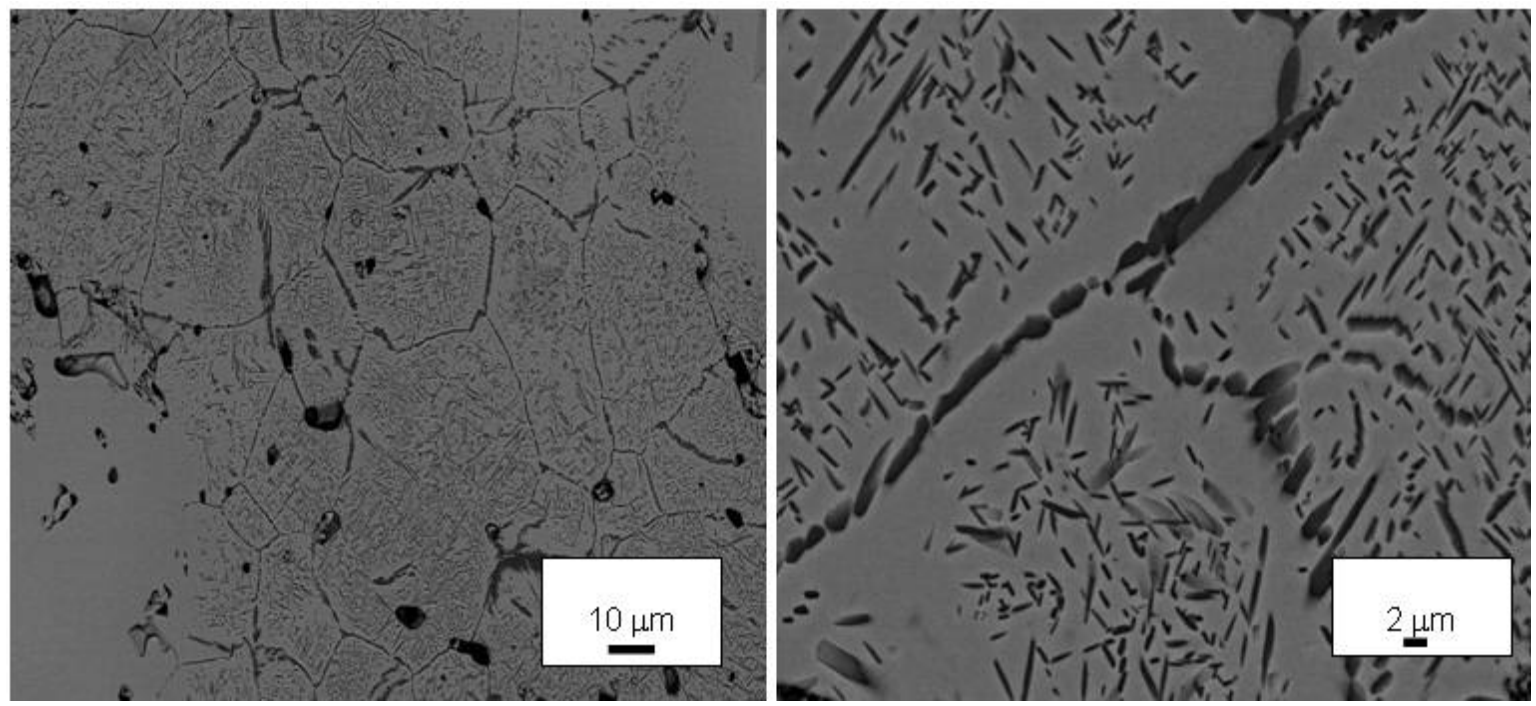

Figura 4: Micrografias das amostras da liga Ti-35Nb-7Zr-5Ta tratadas a $1100^{\circ} \mathrm{C}$ por três horas e resfriados ao forno.

A Figura 5 mostra as regiões na amostra tratada a $1100{ }^{\circ} \mathrm{C}$ durante $3 \mathrm{~h}$ e resfriada ao forno onde foram realizadas análises por EDS. A Tabela 1 apresenta os resultados da análise quantitativa dos elementos. Observa-se a redução do teor dos elementos $\beta$ estabilizadores ( $\mathrm{Nb}$ e Ta) e aumento do teor de $\mathrm{Ti}$, a partir de regiões essencialmente beta (1), bifásica (2) e essencialmente $\alpha$, nos contornos de grão (2). 


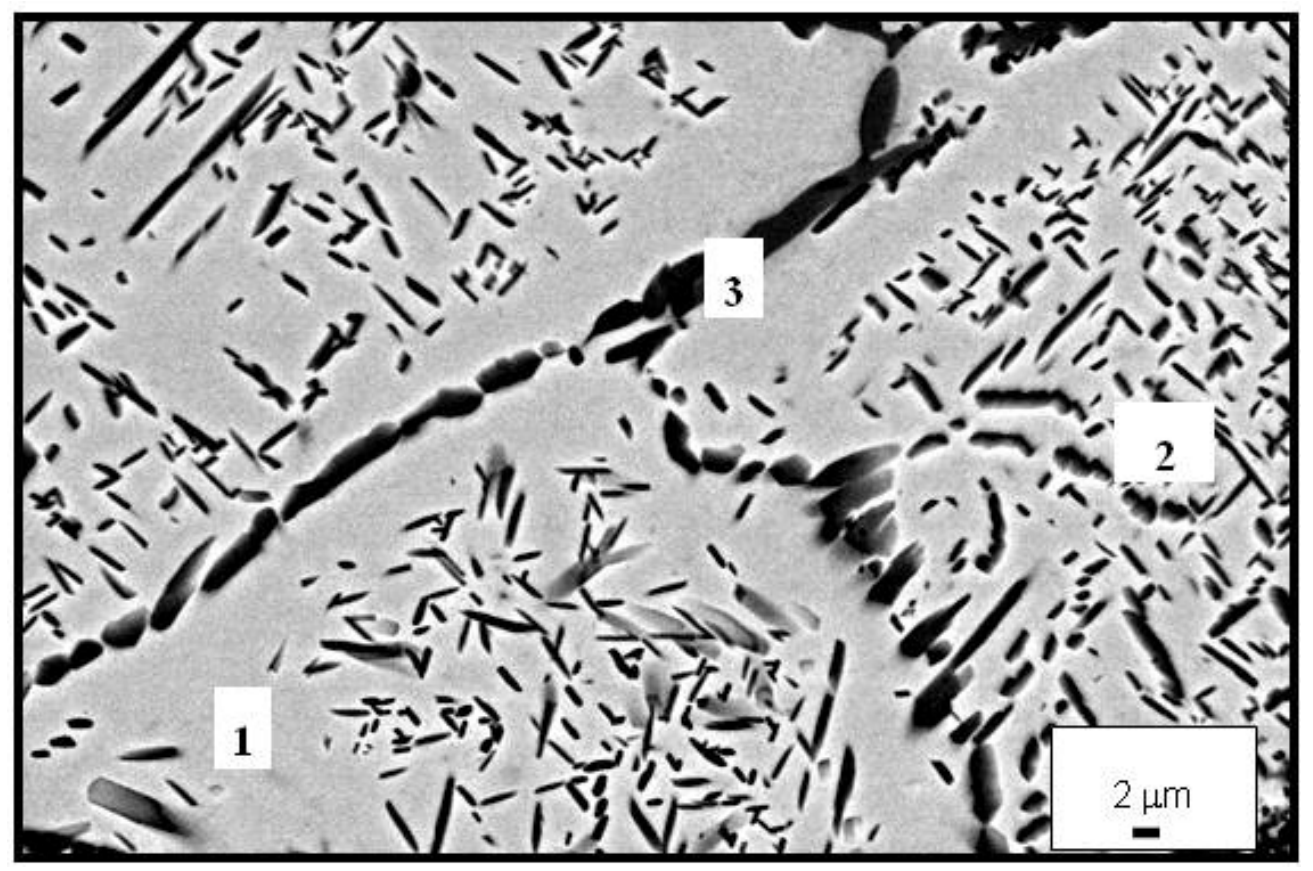

Figura 5: Regiões Analisadas por EDS na liga Ti-35Nb-7Zr-5Ta.

Tabela 1. Teores de Ti, Nb, Ta e Zr nas regiões analisadas (EDS).

\begin{tabular}{ccccc}
\hline Região & $\mathrm{Ti}(\%$ em peso) & $\mathrm{Nb}(\%$ em peso) & $\mathrm{Ta}(\%$ em peso $)$ & $\mathrm{Zr}$ ( \% em peso) \\
\hline$(1)$ & 56,6 & 34,6 & 2,1 & 6,8 \\
$(2)$ & 76,1 & 16,5 & 1,6 & 6,2 \\
$(3)$ & 81,7 & 10,9 & 1,2 & 6,2 \\
\hline
\end{tabular}

Os resultados da análise de citotoxicidade ("in vitro") são apresentados na Figura 6, baseados no percentual de células vivas, para as diferentes concentrações de extrato das amostras sinterizadas, do grupo de referência clínica, bem como dos controles negativo e positivo.

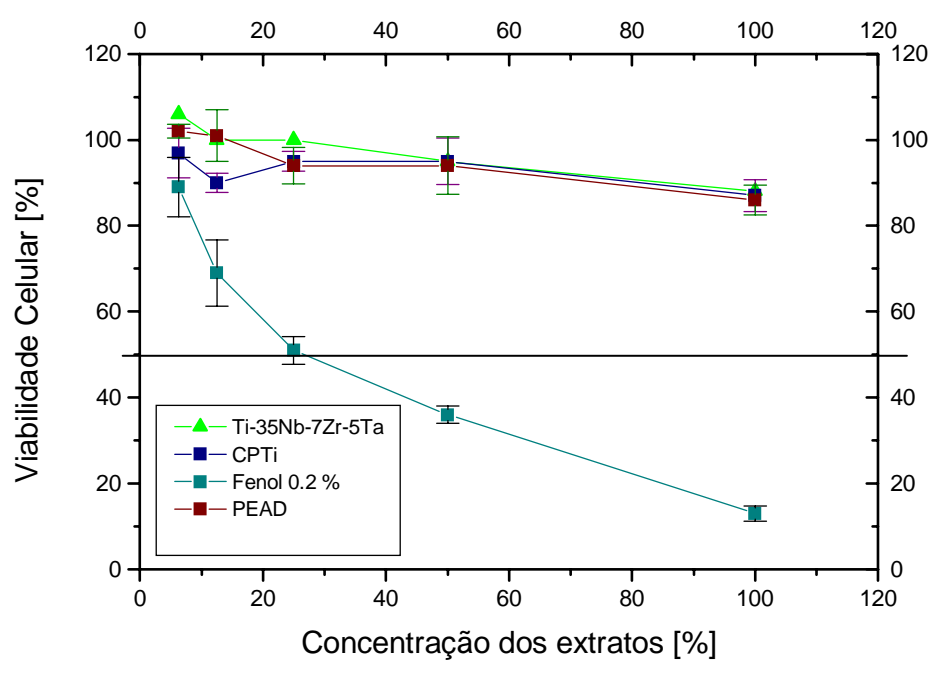

Figura 6: Viabilidade celular versus concentração dos extratos para amostras da liga TI-35Nb-7Zr-5Ta. 
Os valores da Tabela 2, a seguir, utilizados para construir o gráfico da Figura 6, detalham a não toxicidade dos materiais da liga Ti-35Nb-7Zr-5Ta, nas diferentes concentrações testadas, bem como para o grupo de referência clínica, além do controle negativo, representado pelo PEAD. O Índice de Citotoxicidade (IC50(\%)) foi determinado como sendo a concentração do extrato do biomaterial que inibe $50 \%$ da incorporação do MTS. O indice foi obtido correlacionando o percentual médio de células vivas contra a concentração dos extratos (Figura 6). O controle positivo (solução fenólica a $0,2 \%$ ) mostrou-se citotóxico $\mathrm{IC}(50 \%)=23$. Os materiais para implantes obtidos da liga Ti-35Nb-7Zr-5Ta, bem como o de referência clínica e o controle negativo, apresentaram percentuais de viabilidade celular bem próximos na concentração do extrato a $100 \%$.

Tabela 2. Resultados do percentual de células vivas obtidos no teste de citotoxicidde dos extratos das ligas de Ti-35Nb-7Zr-5Ta, do material de referência clínica (Ticp) além dos controle positivo e negativo envolvidos neste teste.

\begin{tabular}{|c|c|c|c|c|}
\hline \multirow{2}{*}{$\begin{array}{c}\text { Concentração } \\
\begin{array}{c}\text { Extratos } \\
(\%)\end{array}\end{array}$} & \multicolumn{4}{|c|}{ Viabilidade Celular (\%) } \\
\cline { 2 - 5 } & Ti-35Nb-7Zr-5Ta & $\begin{array}{c}\text { C. Positivo } \\
\text { (Fenol 0.2\%) }\end{array}$ & $\begin{array}{c}\text { C. Negativo } \\
\text { (PEAD) }\end{array}$ & CpTi, grade 2 \\
\hline 100 & $88 \pm 2,59$ & $15 \pm 1,72$ & $86 \pm 3,48$ & $87 \pm 3,63$ \\
\hline 50 & $95 \pm 5,46$ & $38 \pm 2,04$ & $94 \pm 6,7$ & $95 \pm 5,34$ \\
\hline 25 & $100 \pm 3,32$ & $51 \pm 3,26$ & $94 \pm 4,26$ & $95 \pm 2,33$ \\
\hline 12,5 & $100 \pm 8,91$ & $69 \pm 7,66$ & $101 \pm 6,01$ & $90 \pm 2,2$ \\
\hline 6,25 & $106 \pm 4,19$ & $87 \pm 6,92$ & $102 \pm 1,66$ & $97 \pm 5,77$ \\
\hline
\end{tabular}

\section{CONCLUSÕES}

As amostras da liga Ti-35Nb-7Zr-5Ta solubilizadas a $1100{ }^{\circ} \mathrm{C}$ apresentaram resultados coerentes com a literatura e indicam um padrão microestrutural que se baseia na presença de grãos beta com precipitados de alfa nos contornos e no interior dos grãos. Uma estrutura beta solubilizada é uma condição importante, pois em geral apresenta menores módulos de elasticidade e a presença dos precipitados de alfa é particularmente interessante para o aumento do desempenho das propriedades mecânicas da liga.

O teste "in vitro" revelou a não citotoxicidade da amostra sinterizada a $1500{ }^{\circ} \mathrm{C}$, demonstrando a segurança da utilização dos metais componentes da liga e da rota utilizada na obtenção das amostras. Uma vez que o processamento metalúrgico da liga já foi dominado e que a não citotoxicidade foi comprovada, a próxima etapa do trabalho inclui as análises “in vivo", visando principalmente aspectos de osseointegração para uma eficiente e efetiva utilização em próteses odontológicas e ortopédicas.

\section{AGRADECIMENTOS}

À FAPESP - Fundação de Amparo à Pesquisa do Estado de São Paulo, pelo suporte técnicocientífico e financeiro, ao DEMAR-FAENQUIL, pelo fornecimento de cavacos de Ta e Nb.

\section{BIBLIOGRAFIA}

[1] LI, S.J., YANG, R., LI, S., HAO, Y.L., CUI, Y.Y., NIINOMI, M., GUO, Z.X., "Wear Characteristics of $\mathrm{Ti}-\mathrm{Nb}-\mathrm{Ta}-\mathrm{Zr}$ and Ti-6Al-4V Alloys for Biomedical Applications”, Wear, v. 257, pp. 869-876, 2004.

[2] KARASEVSKAYA, O.P, IVASISHIN, O.M., SEMIATIN, S.L., MATVIYCHUK, YU.V., "Deformation Behavior of beta-titanium Alloys", Materials Science and Engineering, v. A354, pp. 121-132, 2003.

[3] ANKEM, S., GREENE, C.A., "Recent Developments in Microstructure: Property Relationships of Beta Titanium Alloys", Materials Science and Engineering, v. A263, pp. 127-131, 1999. 
[4] GEETHA, M., MUDALI, A.K., GOGIA, A.K., ASOKAMANI, R., RAJ, B., "Influence of Microstructure and Alloying Elements on Corrosion Behavior of Ti-13Nb-13Zr Alloy”, Corrosion Science, 2003

[5] EYLON, et al., "Issues in the Development of Beta Titanium Alloys", Journal of Metals, v. 46, n. 7, pp. 14-15, 1994.

[6] SAKAGUCH, N, NIINOMI, M., AKAROY T., "Tensile Deformation of Ti-Nb-Ta-Zr", Biomedical Alloys, Materials Transactions, v. 45, n. 4, pp. 1113-1119, 2004.

[7] WILLIAMS, et al., "The phase as an Example of an Unusual Shear Transformation", Metallurgical Transactions, v. 4, pp. 2701-2708, 1973.

[8] SAWASE, T., HAI, K., BABA, K., HATADA, R., ATSUTA, M. "Spectroscopic Studies of Three Osseointegrated Impmants”, Journal of Denstistry, v. 16, pp. 119-124, 1998.

[9] OLIVEIRA, PULEO, D.A., NANCI, A., Understanding and Controlling the bone-implant Interface, Biomaterials, v. 20, n. 23-24, pp. 2311-2321, 1999.

[10] SONG, et al., "Theoretical Study of the Effects of Alloying Elements on the Strength and Modulus of $\beta$ Type bio-titanium Alloys", Materials Science \& Engineering - A - Structural Materials: Properties, Microstructure and Processing, v. 260, n. 1-2, pp. 269-274, 1999.

[11] OKAZAKI, Y., et al., "Surface Analysis of Ti-15Zr-4Nb-4Ta after Implantion in Rat Tibia". Biomaterials, v. 22, pp. 599-607, 2001.

[12] BOREFREUND, P. “A Simple Quantitative Procedure using Monolayer Cultures for Cytotoxicity Assay (HTD/NR-90)", Journal of Tissue Culture Methods, v. 9, pp. 7-9, 1984.

[13] BARLTROP, et al., "5-(3-carboxymethoxyphenyl)-2-(4,5-dimethylthiazolyl)-3-(4-sulphophenyl) tetrazolium, Inner Salt (MTS) and Related Analogs of 3-(4,5-dimethylthiazolyl)-2,5diphenyltetrazolium Bromide (MTT) Reducing to Purple water-soluble Formazans as cell-viability Indicators”, Bioorganic \& Medicinal Chemistry Letters, vol. 1, n. 11, pp.611-614, 1991.

[14] INTERNATIONAL ORGANIZATION FOR STANDARDIZATION, ISO 10993-5, Biological Evaluation of Medical Devices. Part 5: Tests for Cytotoxicity: in Vitro Methods, 1993.

[15] TADDEI, E.B., HENRIQUES, V.A.R, SILVA, C.R.M, CAIRO, C.A.A., "Sinterização a Vácuo da Liga Ti-35Nb-7Zr-5Ta”, Revista Brasileira de Aplicações de Vácuo, v. 23, n. 2, pp. 68-72, 2004.

[16] TADDEI, E.B., Henriques, V.A.R, SILVA, C. R. M, CAIRO, C.A.A., "Study of the Ti-35Nb-7Zr-5Ta Sintering”, In: Anais Congresso da Sociedade Brasileira de Microscopia e Microanálise, Caxambu, Brasil, 2003.

[17] TADDEI, E.B, Henriques, V.A.R, SILVA, C.R.M, CAIRO, C.A.A., "Production of new Titanium Alloy for Orthopedic Implants”, Materials Science and Engineering: C, v. 24, pp. 683-687, 2004.

[18] TADDEI, E.B., HENRIQUES, V.A.R, SILVA, C.R.M, CAIRO, C.A.A., "Characterization of Ti-35Nb7Zr-5Ta Alloy Produced By Powder Metallurgy”, Materials Science Forum, pp. 498-499, 2005. 